\title{
Untreated hypertension can lead to memory loss by cutting down on blood flow to the brain
}

\author{
Janyna M. Mercado, PhD, and Robin Hilsabeck, PhD
}

\begin{abstract}
What is hypertension?
Hypertension occurs when the blood is under increased pressure, pushing against the walls of your blood vessels. Systolic pressure, the top number of a blood pressure reading, measures the pressure during a heart beat. The bottom number, the diastolic pressure, measures the pressure between heart beats. A normal blood pressure is defined as $120 / 80$ or lower. Blood pressure between 120 to $140 / 80$ to 90 is "pre-hypertension" and any thing over 140/90 is definite hypertension.
\end{abstract}

\section{Is high blood pressure a big problem?}

The number of adults in the United States with high blood pressure (hypertension) has increased 30\% over the last decade. At least 65 million people (one-third of adults) in America suffer from hypertension. Hypertension does not usually cause symptoms, so many adults who have hypertension may not even be aware of it. When left untreated, hypertension can lead to coronary heart disease, heart failure, stroke, kidney failure, and other problems such as memory loss. More information about memory loss can be found on the next page.

\section{How can hypertension cause memory loss and other problems?}

Hypertension can cause damage to blood vessels by causing a build-up inside the blood vessels, making them narrow. This restricts the amount of blood that can flow through them. If the narrowed blood vessel becomes blocked such that no blood can get through, this can lead to a heart attack or a stroke. Even reduced blood flow to the brain can have damaging effects. The brain must have a certain amount of blood flow to work normally. About one quart of blood normally flows through the brain every minute. If the amount of blood flow is less than it should be, the brain cannot work efficiently. This can lead to memory loss and other symptoms.

\section{What kind of research was done?}

In this issue of Neurology, Jennings and colleagues ${ }^{1}$ evaluate the effects of hypertension on blood flow to parts of the brain involved in memory. They studied 37 people with hypertension and 59 people with normal blood pressure. Two types of memory were tested in these study participants: spatial and verbal memory. Spatial memory was measured by asking participants to remember the position of items seen on a computer screen. Verbal memory was measured by asking participants to remember words. While participants were performing these memory tests, the blood flow through the brain was measured using a brain scan called positron emission tomography (PET). PET allows researchers to determine which parts of the brain are most active during a task, because active areas receive increased blood flow.

\section{What did the study find?}

The researchers found that when people with hypertension perform memory tasks, they have less blood flow to parts of the brain involved in memory and more blood flow to other brain regions than people with normal blood pressure. Despite the differences in blood flow, the performance on the memory tests was the same in both groups. The investigators believe that this is because the hypertensive group was able to compensate for the decreased blood flow to the memory areas of the brain by increasing blood flow to other areas. It is possible that this ability to compensate can only go so far. Increasing damage to the brain blood vessels caused by untreated hypertension could eventually lead to memory loss because non-memory areas of the brain are not able to keep up.

What does this mean for me? The differences in blood flow between people with hypertension and people with normal blood pressure may explain why people with hypertension may develop memory problems. It is important for all adults to have blood pressure checked regularly to prevent many serious health problems. If your blood pressure is consistently high, you should talk with your doctor about the best treatment for you. 


\section{What are the different types of memory?}

Memory is a person's ability to remember information. It is commonly divided into three major types: short-term, long-term, and working memory. Short-term memory is a person's ability to remember new information. For example, when directory assistance gives us a telephone number, we may forget it before we try to dial it. Longterm memory refers to the ability to remember things that were learned in the past. For example, some people have problems remembering the name of a person they have not seen for a long time. Short-term memory is affected more by aging than long-term memory.

Working memory involves doing two things at once. Studies show this type of memory is also affected by aging. For example, think about trying to subtract two big numbers in your head. You need to hold the numbers in your memory at the same time that you are making computations involving "borrowing." When you focus on the subtraction process, you may forget the original numbers you were working with. This seems to create a drain on your memory capacity, or a kind of overload.

\section{What causes memory loss?}

Although problems with memory become increasingly common as people age, most people never develop severe memory problems or dementia unless they have a disease or injury. Some of these include Alzheimer disease, head injury, seizures, alcoholism, brain infections or tumors, and stroke; certain medications can also cause memory loss. Another reason may be simple disuse. The table lists
Table Why do I forget? Research indicates several common reasons

Distraction interrupts memory processing

Sensory losses-vision and hearing deficits create information intake problems

Fatigue decreases attention span

Medication may slow mental functioning

Emotion factors (especially anxiety and depression) can interfere with memory

Viewing things as not important reduces motivation to remember

Having a lot to remember creates an overload and concern about our ability to remember

common reasons why people have trouble remembering things.

\section{How can I help myself keep a healthy working memory?} Research shows that many things affect how well people remember, at any age. If you know what they are, you can use this information to help your own memory functions. For example, when you are upset, you cannot concentrate well and so may not "learn" what you ultimately want to remember. Sometimes it seems that a person's memory is not working well, but the real reason is that the person is distracted. For example, if you enter a room to get something and the telephone rings, you may forget why you went into the room.

When you do not pay attention, you are not likely to register information in the first place. Paying attention takes effort. Think of the times you rush out the door, forgetting something. Perhaps you need to slow down and pause. For example, do you ever wonder whether you have already done something, such as turning the oven off or turning the light out in the basement? To increase your ability to remember, you need to pay attention to what you are doing, so that it will register in your memory.

In one study, researchers found that people were less likely to develop dementia if they participated in some type of leisure time activity. The chances of developing dementia got lower with each additional activity a person participated in. To lower your chances of developing severe memory loss, the more activities you are involved in throughout your life, the lower your risk may be. This suggests that just as with physical health, a healthy memory requires you to use it or lose it!

\section{What should I do if I am} concerned about my memory? If you or your family is concerned that you may have a memory problem, you should talk to your physician. It is important to write down examples of the problems you are having. It is also important to take a friend or family member with you to the appointment to help provide information to the doctor that you may not remember.

\section{For more information}

American Academy of Neurology www.aan.com

American Academy of Neurology Foundation www.thebrainmatters.org

\section{Reference}

1. Jennings JR, Muldoon MF, Ryan C, et al. Reduced cerebral blood flow response and compensation among patients with untreated hypertension. 2005;64:1358-1365. 


\section{Neurology}

\section{Untreated hypertension can lead to memory loss by cutting down on blood flow to the brain}

Janyna M. Mercado and Robin Hilsabeck

Neurology 2005;64;E28-E29

DOI 10.1212/WNL.64.8.E28

\section{This information is current as of April 25, 2005}

\section{Updated Information \&}

Services

Permissions \& Licensing

Reprints including high resolution figures, can be found at: http://n.neurology.org/content/64/8/E28.full

Information about reproducing this article in parts (figures,tables) or in its entirety can be found online at:

http://www.neurology.org/about/about_the_journal\#permissions

Information about ordering reprints can be found online:

http://n.neurology.org/subscribers/advertise

Neurology ${ }^{\circledR}$ is the official journal of the American Academy of Neurology. Published continuously since 1951, it is now a weekly with 48 issues per year. Copyright . All rights reserved. Print ISSN: 0028-3878. Online ISSN: 1526-632X.

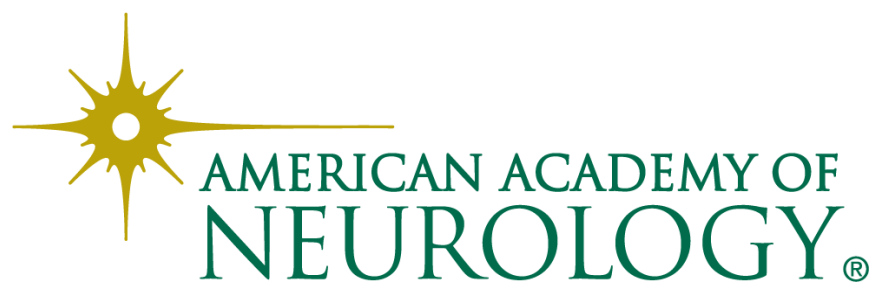

